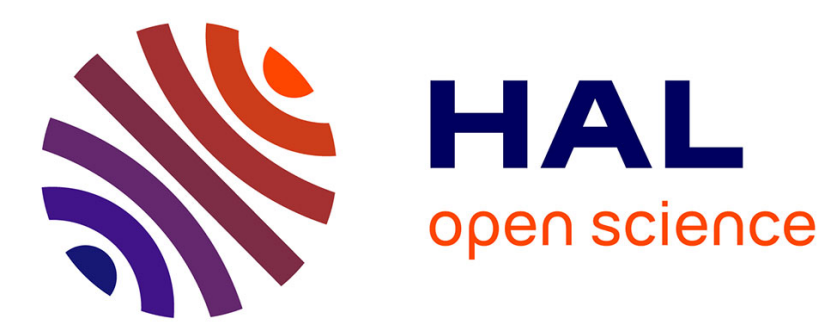

\title{
Closed state of both binding domains of homodimeric mGlu receptors is required for full activity.
}

Julie Kniazeff, Anne-Sophie Bessis, Damien Maurel, Hervé Ansanay, Laurent Prézeau, Jean-Philippe Pin

\section{To cite this version:}

Julie Kniazeff, Anne-Sophie Bessis, Damien Maurel, Hervé Ansanay, Laurent Prézeau, et al.. Closed state of both binding domains of homodimeric mGlu receptors is required for full activity.. Nature Structural and Molecular Biology, 2004, 11 (8), pp.706-13. 10.1038/nsmb794 . hal-00318999

\section{HAL Id: hal-00318999 \\ https://hal.science/hal-00318999}

Submitted on 5 Sep 2008

HAL is a multi-disciplinary open access archive for the deposit and dissemination of scientific research documents, whether they are published or not. The documents may come from teaching and research institutions in France or abroad, or from public or private research centers.
L'archive ouverte pluridisciplinaire HAL, est destinée au dépôt et à la diffusion de documents scientifiques de niveau recherche, publiés ou non, émanant des établissements d'enseignement et de recherche français ou étrangers, des laboratoires publics ou privés. 


\section{Closed state of both binding domains of homodimeric mGlu receptors is required for full activity}

Julie KNIAZEFF ${ }^{1}$, Anne-Sophie BESSIS ${ }^{1,3}$, Damien MAUREL ${ }^{1,2}$, Hervé ANSANAY ${ }^{2}$, Laurent PREZEAU ${ }^{1}$ and Jean-Philippe PIN $^{1 \dagger}$

${ }^{1}$ Laboratory of Functional Genomic, Department of Molecular Pharmacology, Centre National de la Recherche Scientifique, Unite Propre de Recherche 2580, 141 rue de la Cardonille, 34094 Montpellier Cedex 5, France. ${ }^{2}$ Cis Bio International, BP 175, F 30203 Bagnols sur Ceze, France.

3: present address: Addex Pharmaceuticals SA, 12, Chemin Des Aulx, CH-1228 Plan les Ouates, Geneva, Switzerland.

${ }^{\dagger}$ : To whom correspondence should be addressed:

Laboratory of Functional Genomic, CNRS UPR-2580,

Department of Molecular Pharmacology, 141 rue de la Cardonille,

F-34094 Montpellier Cedex 5, France.

Tel: +33 467142933 (Lab) 2988 (Office)

Fax: +33467542432

e.mail: jppin@ccipe.cnrs.fr

Abstract: 137 words (137)

Main text: 4045 words (4217)

Introduction: 676 words (678)

Results: 1989 words (2021)

Discussion: 1380 words (1518)

Methods: 838 Words (895)

Legends: 986 words (1092)

Total: 6006 words (6341)

References: 42 (42)

(Numbers into parenthesis correspond to those of the previous version of the manuscript) 


\begin{abstract}
:
Membrane receptors, which are key components in signal transduction, often function as dimers. These include some $\mathrm{G}$ protein-coupled receptors such as metabotropic glutamate ( $\mathrm{mGlu}$ ) receptors that possess large extracellular domains (ECDs) where agonists bind. How agonist binding in dimeric ECDs activates the effector domains remains largely unknown. The structure of the dimeric ECDs of $\mathrm{mGlu}_{1}$ solved in the presence of agonist revealed two specific conformations in which either one or both protomers are in an agonist-stabilized closed form. Here we examined whether both conformations correspond to an active form of the full-length receptor. Using a system that allows the formation of dimers made of a wildtype and a mutant subunit, we show that the closure of one ECD per dimer is sufficient to activate the receptor, but the closure of both ECDs is required for full activity.
\end{abstract}




\section{Introduction}

Cell surface receptors play major roles in signal transduction. Many of them exist as dimers but the precise conformational changes leading to their activation remain largely unknown. Some of these receptors possess a large ECD involved in agonist binding. Conformational changes in ECDs resulting from agonist binding have to affect the conformation of the effector domain for the signal to be transduced inside the cell.

Structures of dimeric ECDs of many membrane receptors, including some tyrosine kinase $(T K)^{1-4}$, guanylate cyclase $(\mathrm{GC})^{5-7}$ and G-protein coupled receptors (GPCRs) ${ }^{8-11}$ have been solved by X-ray crystallography in the absence or presence of agonists. Accordingly, initial steps leading to receptor activation were proposed. However, this often remains to be confirmed in full-length receptors.

The $\mathrm{mGlu}_{1}$ receptor is one of the dimeric receptors for which important information have been obtained by X-ray crystallography ${ }^{8,9}$. This receptor belongs to the class $C$ GPCRs that includes the eight mGlu receptors, the $\gamma$-aminobutyric acid type $B\left(G A B A_{B}\right)$, the $\mathrm{Ca}^{2+}$ sensing and some taste and pheromone receptors ${ }^{12}$. In addition to the heptahelical domain (HD) common to all GPCRs, class C receptors have a large ECD composed of a Venus Flytrap domain (VFT) where agonists bind and a cysteine-rich domain (CRD).

The resolution of the structure of $\mathrm{mGlu}_{1} \mathrm{VFT}^{8,9}$, expressed as a soluble protein, confirmed several features previously suggested ${ }^{13,14}:$ i) this domain is structurally similar to some bacterial periplasmic proteins and is composed of two lobes separated by a cleft where ligand binds; ii) the VFT, in an open conformation in the absence of ligand or with bound antagonist, can adopt a closed conformation upon agonist binding; iii) these soluble VFTs are associated in homodimers at the level of their lobe-I by hydrophobic interactions and a disulfide bridge.

The most interesting observation is the existence of two possible relative orientations of the VFTs within the dimer. A first orientation is observed in the absence of agonist or in the presence of an antagonist, and is therefore called "Resting". In that case, both VFTs are open (Roo) and lobes-II, that connect the HD, are far apart (Fig. 1). A second orientation is observed in the presence of agonists, and is therefore called "Active". In that case either one (Aco) or both (Acc) VFTs are in a closed state and lobes-II become closer and directly contact each other (Fig. 1). Moreover, binding of a cation like $\mathrm{Gd}^{3+}$, which is described as an $\mathrm{mGlu}_{1}$ potentiator, at the lobe-II interface has been proposed to favor the Acc conformation ${ }^{8}$.

We have previously given evidence that, in full-length receptors, agonists act by stabilizing a closed state in at least one VFT whereas antagonists prevent such closure. Indeed, the insertion of two cysteines expected to lock the VFT of the GABA $A_{B 1}$ receptor closed lead to a constitutively fully active receptor ${ }^{15}$. Moreover, mutation of residues that 
prevent the closure of the mGlu 8 VFT upon binding of two distinct antagonists, allows these molecules to act as full agonists ${ }^{16}$. However, it is still unknown whether both Acc and Aco conformations of the dimer of VFTs correspond to active receptor conformations. It is also unclear whether binding of two agonists per dimer is required for class C GPCR activation. In the case of the heterodimeric $G_{A B A}$ receptor that is composed of the $G A B A_{B 1}$ and $G A B A_{B 2}$ subunits, it was shown that agonist binding occurs in the $\mathrm{GABA}_{\mathrm{B} 1}$ VFT only ${ }^{17}$, but what about homodimeric mGlu receptors?

In the present study we have examined whether the binding of one or two agonists are required to activate homodimeric mGlu receptors. We have also examined whether the Aco conformation of the dimer of VFTs corresponds to a fully active receptor. To that aim we have developed a system that allows the surface expression of dimeric combinations composed of two defined subunits, with or without specific mutations. Here we show that although binding of a single agonist is sufficient to activate $\mathrm{mGlu}_{5}$ receptor, a second is required for full activity. Our data also show that only the Acc conformation leads to full activity, the Aco conformation corresponding to a partially active state of the dimer. 


\section{Results}

To examine the specific role and possible conformation of each VFT in a dimeric mGlu receptor, it is necessary to have access to dimeric receptors composed of two defined subunits, one with and one without mutations affecting ligand recognition.

\section{Generation of "heterodimeric" $m$ Glu $u_{5}$ receptor at the cell surface}

To that aim we took advantage of the quality control system of the $G_{A B A}$ receptor $^{18-}$ 20. We first replaced the $C$-terminal tail of $m_{G l u_{5}}$ by that of the $G_{A B A}$ subunit containing the endoplasmic reticulum (ER) retention signal RSRR (Fig. 2a). As expected, the mG5C1 chimera was not targeted to the cell surface as shown by both immunofluorescence and ELISA experiments performed on intact cells (Fig. 2b,c). Mutation of the ER retention signal into $A S A R^{19}$ allows the receptor to reach the cell surface and to activate phospholipase $C$ (PLC) (quisqualate $\mathrm{EC}_{50}=56 \pm 10 \mathrm{nM}$ ), demonstrating that the $\mathrm{C}$-terminal tail of $\mathrm{GABA}_{\mathrm{B} 1}$ does not prevent coupling to $\mathrm{Gq}$ (Fig. 2d).

A second $\mathrm{mGlu}_{5}$ chimera was generated in which the C-terminal tail was replaced by that of $\mathrm{GABA}_{\mathrm{B} 2}$ (Fig. 2a). This C-terminal tail is known to possess a determinant able to mask the $E R$ retention signal of $G_{A B A_{B 1}}$ in $G_{A B A_{B 1}}: G A B A_{B 2}$ heterodimers ${ }^{18,19}$. When expressed alone, this $\mathrm{mG} 5 \mathrm{C} 2$ chimera is correctly targeted to the cell surface and is still functional (Fig. 2b-d) (quisqualate $\mathrm{EC}_{50}=69 \pm 16 \mathrm{nM}$ ).

When HA-mG5C1 was co-expressed with myc-mG5C2, HA-mG5C1 reached the cell surface (Fig. 2b,c) demonstrating that $\mathrm{GABA}_{\mathrm{B} 2}$ tail exerts its action even in the $\mathrm{mGlu}_{5}$ environment. Because $m \mathrm{mlu}_{5}$ dimers are linked by a disulfide bridge ${ }^{14,21,22}$, it is likely that the dimers formed in the ER are stable even at the cell surface. As such, in cells expressing both $\mathrm{mG} 5 \mathrm{C} 1$ and $\mathrm{mG} 5 \mathrm{C} 2$, one would expect that $\mathrm{mG} 5 \mathrm{C} 1$ homodimers are retained in the $\mathrm{ER}$, whilst mG5C2 homodimers as well as $\mathrm{mG} 5 \mathrm{C} 1: \mathrm{mG} 5 \mathrm{C} 2$ heterodimers would reach the cell surface (Fig. 3a).

In agreement with this proposal the presence of $\mathrm{mG} 5 \mathrm{C} 1 \mathrm{mG} 5 \mathrm{C} 2$ heterodimers at the cell surface, was firmly established on intact cells, as based on the $\mathrm{HTRF}^{\circledR}$ technology (homogeneous time resolved-FRET) ${ }^{23}$. To that aim we used anti-HA and anti-myc antibodies labeled with donor and acceptor fluorophores, respectively ${ }^{24}$ (see methods). A clear FRET signal was observed with $\mathrm{HA}-\mathrm{mG} 5 \mathrm{C} 1$ and myc-mG5C2, similar to the signal measured with $\mathrm{HA}_{-}-\mathrm{GAA}_{\mathrm{B} 1}$ and myc-GABA $\mathrm{B}_{2}$ (Fig. 3b). At an equivalent expression level (Fig. 3c), no such signal was observed when the two tagged proteins were independently labeled in different cells or when HA-mG5C2 was co-expressed with myc-V2 vasopressin receptors (Fig. 3b). The FRET signal of $m G 5 C 1: m G 5 C 2$ is directly proportional to the amount of $m G 5 C 1$ at the cell surface. Furthermore, in these same cells, no significant FRET signal could be measured 
between two HA-mG5C1 when using a mixture of anti-HA antibodies labeled with either fluorescent donor or acceptor molecules (Fig. 3d), demonstrating that HA-mG5C1 homodimers, (or tetramers composed of two mG5C1:mG5C2 heterodimers) where not present at the cell surface. By contrast, a clear signal was measured using the same anti-HA antibodies in cells expressing $\mathrm{HA}-\mathrm{mGlu}_{5}$ homodimers $^{24}$.

mGlu 5 mutants insensitive to agonists

We next aimed to generate mGlu$_{5}$ mutants that can no longer be activated by agonists in order to produce dimers with a single wild-type agonist binding site. Accordingly, mutations were introduced either in lobe-II (Y222A+D304A), or in lobe-I (S151A+T174A, or $\mathrm{Y} 64 \mathrm{~A}+\mathrm{T} 174 \mathrm{~A}$ ), as based on a $3 \mathrm{D}$ model of the $\mathrm{mGlu}_{5} \mathrm{VFT}$ generated as previously described $^{16}$ (Fig. 4a). These three mutants were called mGlu ${ }_{5}$ YADA, SATA and YATA, respectively. These mutations were also introduced into both the HA- and the myc-mG5C2 chimeras. Cells expressing any of these mutants were not able to produce IP (Inositol phosphates) even upon stimulation with $10 \mathrm{mM}$ glutamate or quisqualate, a highly potent mGlu $_{1}-$ mGlu $_{5}$ selective agonist (Fig. 4b). This is most likely due to the inability of these agonists to activate the receptor since all mutant receptors were found at the cell surface at a density similar to the non-mutated controls, as revealed by ELISA (Data not shown).

One agonist per dimer is sufficient to activate the receptor

According to the data described above, any measured response in cells expressing mG5C1 and mG5C2-YADA will be generated by the heterodimer mG5C1:mG5C2-YADA (Fig. 5a). As shown in Figure 5b, a biphasic dose-response curve was observed. The first response occurred with an $\mathrm{EC}_{50 \mathrm{~L}}$ of $304 \pm 152 \mathrm{nM}$, higher than that measured on the control dimer $(48 \pm 8 \mathrm{nM})$ and plateaued at $25-30 \%$ of the maximal response of the control dimer. This is consistent with a 3 fold decrease in coupling efficacy since the IP response was previously shown to be directly proportional to the amount of $\mathrm{mGlu}_{5}$ receptors at the cell surface ${ }^{25}$. A second response occurred at higher concentrations of quisqualate $\left(E_{50 \mathrm{H}} 208 \pm 32 \mu \mathrm{M}\right)$ and reached a maximum close to $80 \%$ of that measured with the control receptor. A similar biphasic response was also obtained when the intracellular $\mathrm{Ca}^{2+}$ signal was measured instead of the IP production (Fig. $5 \mathrm{c}$ ). Since the $\mathrm{EC}_{50 \mathrm{~L}}$ is close to that measured on the wildtype receptor, it is likely that the first component of this response results from quisqualate binding in the wild-type subunit only.

\section{A second agonist per dimer is needed for maximal receptor activity}

The second phase of the response measured with the mG5C1:mG5C2-YADA heterodimer is likely due to quisqualate activation of the second mutated VFT, an effect 
made possible by the agonist occupied wild-type VFT. In agreement with this proposal, the $\mathrm{EC}_{50 \mathrm{~L}}$ of quisqualate did not depend on the mutations introduced in the mutated subunit $(304 \pm 152,301 \pm 115$ and $218 \pm 80 \mathrm{nM}$ for the combination containing mG5C2-YADA, YATA and SATA, respectively), but $\mathrm{EC}_{50 \mathrm{H}}$ largely varies depending on the mutant subunit used (208 $\pm 32,972 \pm 108$ and $1576 \pm 246 \mu \mathrm{M}$ for $\mathrm{mG} 5 \mathrm{C} 2-$ YADA, YATA and SATA, respectively) (Fig. $5 d)$.

Accordingly, although one ligand appears sufficient to activate the receptor, the activation is partial, and only binding of two agonists can maximally activate such dimeric receptors.

\section{The Aco conformation leads to partial activity of the receptor}

There are two possibilities to explain the observation that one ligand per dimer partially activates the receptor assuming the bound VFT is in a closed state. A first possibility is that the Aco conformation is sufficient to partially activate the receptor. The second possibility is that the closed liganded VFT can in turn favor the closure of the second unliganded VFT leading to a certain proportion of the monoliganded receptors in the active Acc state.

To examine if the Aco state is sufficient to activate the receptor, we generated a mGlu dimer in which one VFT can be stabilized in a closed state by an agonist, and the second VFT can be maintained open by an antagonist. To that aim, we generated a subunit composed of the $\mathrm{mGlu}_{2} \mathrm{VFT}$, the $\mathrm{HD}$ of $\mathrm{mGlu}_{5}$ and the C-term of $\mathrm{GABA}_{\mathrm{B} 2}$ (mG2/5C2, Fig. $6 a)$. Such a chimeric receptor can reach the cell surface, be activated by the selective $\mathrm{mGlu}_{2}$ agonist DCG-IV, and be antagonized by the selective mGlu $_{2}$ antagonists PCCG-IV, MCCG-I and LY341495 $\left(\mathrm{ref}^{26}\right)$. Moreover, this chimera is insensitive to the mGlu 5 agonist quisqualate and bring to the cell surface $\mathrm{mG} 5 \mathrm{C} 1$ (data not shown).

As illustrated in Figure 6, quisqualate activates the mG5C1:mG2/5C2 heterodimers $\left(E C_{50}=251 \pm 109 \mathrm{nM}\right.$ ), an effect that is not affected by $\mathrm{mGlu}_{2}$ selective antagonists (Fig. $6 \mathrm{c}$ )(quisqualate $\mathrm{EC}_{50}=251 \pm 109 ; 219 \pm 53 ; 275 \pm 105$ and $209 \pm 7 \mathrm{nM}$ under control condition and in the presence of PCCG-IV, MCCG-I or LY341495, respectively). As we will see below, this is not due to the inability of these antagonists to act in $\mathrm{mG} 2 / 5 \mathrm{C} 2$ within such a heterodimer (Fig. 8). Assuming the antagonist prevent the closure of the mG2/5C2 VFT, this demonstrates that the Aco state of the VFT dimer is sufficient to partially activate the receptor.

\section{Signal transduction within the "heterodimer"}

In a homodimeric receptor, both HDs are identical and potentially share the same capacity to activate $\mathrm{G}$ proteins. Accordingly, and in agreement with previous studies ${ }^{27}$, 
dimers in which one HD only was mutated in its i3 loop (F767S) to prevent G-protein coupling $^{28,29}$ (mG5C1-i3 + mG5C2 or mG5C1 + mG5C2-i3) are still functional but the maximal stimulation is decreased by about $50 \%$ despite a similar expression level of all combinations (Fig. 7a).

Accordingly, one possible interpretation for the partial activity of the dimer is that an agonist liganded VFT leads to the activation of either the HD of the same subunit (cisactivation, Fig. 7b) or that of the other subunit (trans-activation, Fig. 7b). Then, full activity can only be obtained upon agonist binding in both VFTs.

In order to determine which mechanism really occurs during the activation process, we examined the effect of the i3 loop mutation in either HD within the heterodimer mG5C1:mG5C2-YADA. Indeed, in the case of cis-activation, the i3 mutation introduced into mG5C1 should prevent the first component of the agonist dose-response curve only. The second component should remain intact. In contrast, in case of trans-activation, such a mutation is expected to suppress the second phase only. The reverse is expected if the i3 mutation is introduced into mG5C2-YADA. As shown in Figure $7 \mathrm{c}$, whether the i3 mutation is introduced in mG5C1 or in mG5C2-YADA, a decrease in the maximal response of both the first and the second phase was observed despite a similar expression level of the different constructs. This indicates that both HDs contribute to the two activated states of the receptor. Accordingly, a single agonist occupied VFT can activate either HDs (or both), consistent with both cis- and trans-activation occurring in these dimeric receptors (Fig. 7d).

\section{The Acc conformation is required for full activity}

Our data demonstrate that two agonists are required for full activation of mGlu receptors, suggesting that both VFTs must reach a closed state. To firmly demonstrate this, we further examined the properties of the $\mathrm{mG} 5 \mathrm{C} 1: \mathrm{mG} 2 / 5 \mathrm{C} 2$ heterodimer. However, when these two subunits are co-expressed, part of the response mediated by glutamate that activates both $\mathrm{mGlu}_{2}$ and $\mathrm{mGlu}_{5}$ VFTs, may result from the activation of $\mathrm{mG} 2 / 5 \mathrm{C} 2$ homodimers (Fig. 8). To avoid this possibility, the $\mathrm{mG} 2 / 5 \mathrm{C} 2$ subunit was mutated in its i3 loop. As shown in Figure $8 \mathrm{a}$, the $\mathrm{mGlu}_{5}$ selective agonist quisqualate stimulated IP formation but its maximal effect was about half of that obtained with the non selective agonist glutamate. Since the IP formation was previously shown to be proportional to the amount of receptors at the cell surface ${ }^{25}$, this finding indicates that selective activation of $\mathrm{mG} 5 \mathrm{C} 1$ leads to a two fold lower coupling efficacy. Further addition of a mGlu 2 agonist (LY354740 or DCGIV) increased the maximal quisqualate effect to reach the response obtained with glutamate (Fig. 8a). Moreover the effect of glutamate is inhibited by $50 \%$ by LY341495 expected to prevent the closure of the mGlu 2 VFT (Fig. 8b), further demonstrating that the closed state of both VFTs is required for full activity. 
Surprisingly, $\mathrm{mGlu}_{2}$ selective agonists (up to $1 \mathrm{mM}$ ) did not on their own activate this receptor combination, suggesting that the closure of the $\mathrm{mGlu}_{2}$ VFT is not able to transactivate the $\mathrm{HD}$ of $\mathrm{mG} 5 \mathrm{C} 1$. This is in contrast to what was observed with the mG5C1:mG5C2-YADA dimer, in which a clear transactivation is observed (Fig. 7c). This is likely due to the chimeric nature of the dimer of VFTs in the mG5C1-mG2/5C2-i3 combination. It is possible that the Aco dimer in which the mGlu 2 VFT is closed is not as stable as that in which the mGlu $\mathrm{VFT}$ is closed, due to the asymmetry of the lobe-II interface in this heterodimer.

To further document that the Acc conformation is required for full activity, the effect of $\mathrm{Gd}^{3+}$ was examined on glutamate dose-response curves performed on the mG5C1:mG5C2YADA heterodimer. As shown in Figure 1, it has been proposed that a cation such as $\mathrm{Gd}^{3+}$ is required to reach/stabilize the Acc conformation ${ }^{8}$. Of interest, we observed an increase in quisqualate potency in generating the second phase of the response in the presence of $\mathrm{Gd}^{3+}$ ( $\mathrm{EC}_{5 \mathrm{OH}} 51 \pm 5 \mu \mathrm{M}$ and $208 \pm 32 \mu \mathrm{M}$, in the presence and absence of $\mathrm{Gd}^{3+}$, respectively), but no change in $\mathrm{EC}_{50 \mathrm{~L}}(442 \pm 201 \mathrm{nM})$. This further supports that the second phase of the dose response curve results from the Acc conformation of the VFT dimer. 


\section{Discussion}

The present study was aimed at determining which of the agonist occupied conformations of the dimer of mGlu VFTs, the Aco and Acc conformations ${ }^{8}$, correspond to the active state of full-length receptor. Our data show that the Aco and Acc conformations correspond to a partially and fully active state of the dimer, respectively.

\section{A method to examine the activation mechanism of dimeric membrane receptors}

To examine the specific role of each VFT in a homodimeric mGlu receptor, we first developed a system allowing cell surface expression of functional dimeric receptors composed of two defined subunits each bearing or not specific mutations. Indeed, we show that the quality control system of the $\mathrm{GABA}_{B}$ receptor ${ }^{18-20}$ can be transferred to the mGlu receptor. Thus, in cells co-expressing $\mathrm{mG5C1}$ and $\mathrm{mG} 5 \mathrm{C} 2$ chimeras that possess the $\mathrm{C}$ terminal tail of $\mathrm{GABA}_{\mathrm{B} 1}$ and $\mathrm{GABA}_{\mathrm{B} 2}$, respectively, we demonstrate the existence of mG5C1:mG5C2 heterodimers at the cell surface. We also show that mG5C1 homodimers do not reach the cell surface. Finally, although mG5C2 homodimers reach the cell surface, the function of these receptors can easily be abolished by specific mutations. Accordingly, in cells expressing these two types of subunits, only the heterodimer is functional. Such a system may well be adapted to other membrane proteins for which the functional significance of dimer formation is still unknown, such as rhodopsin-like GPCRs.

A single agonist is sufficient to activate mGlu receptors, but two are required for full activity

Using this system we show that binding of a single agonist is sufficient to activate $\mathrm{mGlu}_{5}$ dimers. This is illustrated by the first component of the agonist dose-response curve in mG5C1:mG5C2 in which mutations have been introduced in the $\mathrm{mG} 5 \mathrm{C} 2$ binding site. This is also confirmed by the effect of a selective mGlu $\mathrm{u}_{5}$ agonist on the $\mathrm{mG} 5 \mathrm{C} 1: \mathrm{mG} 2 / 5 \mathrm{C} 2-\mathrm{i} 3$ heterodimer. However, the activation is partial and only when a second agonist binds to the associated subunit was the receptor fully active. Surprisingly, in heterodimers containing a subunit mutated in the binding site, application of agonists appears to activate the mutated subunit at concentration where no effect was seen on homodimeric mutated receptors. Accordingly, agonist binding to the wild-type VFT either largely increases agonist affinity to the open state mutated VFT, and/or allows the agonist binding to stabilize the closed state of the mutated subunit by decreasing the energy required for isomerization.

The Aco and Acc conformations correspond to partially and fully active receptors, respectively 
Our data indicate that the partial activity measured with a mono-liganded dimer corresponds to the Aco conformation of the dimer of VFTs. Indeed, agonists are well accepted to stabilize the closed conformation of the VFT, whereas antagonists prevent such a closure $8,9,15,16$. As such a receptor in which an agonist occupies one VFT whereas an antagonist is bound to the other is expected to have one VFT in the closed state and the other in the open state. As shown with the mG5C1:mG2/5C2 response measured in the presence of a mG5C1 agonist and a mG2/5C2 antagonist, such a liganded dimer displays the same partial activity as a receptor activated by a single agonist. Several arguments are also consistent with the fully active receptor corresponding to the Acc conformation. In the case of the mG5C1:mG2/5C2 heterodimer, where agonist occupation of both VFTs is required for full activity, and this activity is only partly inhibited in the presence of an antagonist acting selectively on $\mathrm{mG} 2 / 5 \mathrm{C} 2$. Moreover, the second phase of the quisqualate response observed with mG5C1:mG5C2-YADA dimer is sensitive to $\mathrm{Gd}^{3+}$, as expected according to the proposed stabilization of the Acc conformation by these cations (Fig. 1$)^{8}$.

\section{Signal transduction within the mGlu dimer}

Partial activity of such dimeric receptors corresponding to the mono-liganded Aco conformation may well result from the activation of a single HD. However our data clearly indicate this is not the case since even when activated by a single agonist, both HDs contribute to the activation of PLC. Accordingly, the closure of one VFT can turn ON either its associated HD and/or that of the other subunit. This conclusion fits perfectly well with the proposal that the change in the relative orientation of the VFTs observed between the "Resting" and the two "Active" states (Fig. 1) force the HDs to interact differently leading to their activation.

The Aco and Acc conformations of the dimer of mGlu1 VFTs were proposed to both correspond to an active state of the receptor ${ }^{9}$. This was based on the similar relative position of the C-terminal ends of these VFTs in both conformations of the dimer. Indeed, these Cterminal ends are connected to the HD via a CDR. So, why is the full activity only observed with the Acc conformation? When comparing the areas of the VFTs that likely face the HDs, a possible explanation can be proposed. Indeed, the relative positions between the areas are different in the Aco and Acc conformations. Then it is possible that the Aco conformation is sufficient for the dimer of HDs to reach a fully active state, but this state would not be well stabilized. Alternatively, the Aco conformation stabilizes another conformation of the dimer of HDs corresponding to a partially active state.

Comparison with the $G A B A_{B}$ receptor 
Like mGlu receptors, the $\mathrm{GABA}_{B}$ receptor is a heterodimer and each subunit is composed of a VFT and a $H D^{17,30-32}$. Our actual knowledge of the activation mechanism of this receptor fits well with the proposed activation mode of mGlu receptors. Indeed, GABA only binds in the $\mathrm{GABA}_{\mathrm{B} 1} \mathrm{VFT}^{17}$, and the closure of this domain is sufficient to activate the receptor ${ }^{15}$. Obviously, in that case, full activity is obtained with a single agonist, in contrast to mGlu receptors. However, we still don't know if the GABA $A_{B 2} V F T$ closes upon GABA $A_{B 1} V F T$ closure. In contrast to the mGlu receptors, in which both HDs plays an equivalent role in Gprotein activation, the $\mathrm{GABA}_{\mathrm{B} 2} \mathrm{HD}$ plays a prominent role, whether this $\mathrm{HD}$ is associated with the $G_{A B A}$ or $G_{B B A} V V_{B 1}^{32,33}$. However, as observed with mGlu receptors, in a $G A B A_{B}$ receptor combination in which both subunits possess the $\mathrm{GABA}_{B 2} \mathrm{HD}$, both HDs play an equivalent role in G-protein coupling ${ }^{27}$.

Why two ligands to activate a receptor?

This is obviously an important question, especially considering that the $G_{A B A}$ receptor needs only one. This may well be the consequence of the maintenance during evolution of homodimer formation in this family of receptors, and as such the direct consequence of symmetry. However, many mGlu receptors play a critical role in fast modulation of synaptic transmission ${ }^{34}$. According to the proposed model for receptor activation, the binding of a first agonist will already be sufficient to partially activate the receptor, therefore rapidly leading to the fully active receptor. This may increase the probability that the receptor is activated by low concentrations of agonist. Another attractive possibility is that the more complex is the activation system, the more possibilities of regulation. For example, controlling the Aco-Acc equilibrium would have direct consequences on receptor activity. $\mathrm{Ca}^{2+}$ appears as a good candidate for such a role, although its action is difficult to analyze due to the multiple cellular consequences resulting from its removal, and also because other cations such as $\mathrm{Mg}^{2+}$ may have a similar effect. Of interest however, $\mathrm{Ca}^{2+}$ has been proposed to either directly activate $\mathrm{mGlu}_{1}$ receptors or to act as a positive modulator $^{35}$.

Very similar to the mGlu receptors are the T1 taste receptors that, like the GABA receptor, also form heterodimers. Whereas the T1R2:T1R3 heterodimer as well as the T1R3 homodimers are responsible for sweet detection ${ }^{36-38}$, the T1R1:T1R3 combination is responsible for umami taste detection ${ }^{37,39}$. It is actually not known where the sweet and amino acid compounds bind in these receptors, but several lines of evidence suggest that they bind in the VFTs. In such receptor heterodimers, the existence of natural ligands interacting specifically with each subunits may offer a nice physiological role for the mechanism proposed here, allowing synergism between the effects of these taste molecules. 


\section{Conclusion}

Structural studies performed with extracellular domains of dimeric receptors often highlight changes in the interacting interface between the subunits during the activation process. In the case of the $\mathrm{mGlu}_{1}$ receptor two possible active conformations have been proposed. Our data demonstrate that whilst both actually correspond to active forms of the receptor, only one, the symmetric Acc conformation, corresponds to the fully active receptor. 


\section{Acknowledgements:}

The authors wish to thank Drs. V. Binet, C. Goudet, P. Rondard (Montpellier), C. Hatton, J. Neyton and P. Paoletti (Paris) for constructive discussions and critical reading of manuscript. The authors wish also to thank Cis Bio International Research group, Bagnols-sur-Cèze, France for the supply of labeled antibodies, and Drs G. Mathis and E. Trinquet from Cis Bio International for their strong support. This work was supported by grants from the CNRS, the Action Incitative "Molécules et Cibles Thérapeutiques" from INSERM, CNRS and the French government, Addex Pharmaceuticals, Fondation Paul Hamel, Comité Parkinson of the Fondation de France. J.K was supported by a CNRS fellowship. 


\section{Methods}

\section{Materials}

L-Glutamic acid was purchased from Sigma. L-Quisqualic acid, MCCG-I ((2S,3S,4S)2-2Methyl-2-(carbxycyclopropyl)G Iy cine ), DCG-IV ((2S, 2'R, 3'R)-2 - (2', 3 ' Dicarboxycyclopropyl)glycine) and LY491395 ((2S)-2-Amino-2-[(1S,2S)-2-carboxycycloprop1-yl]-3-(xanth-9-yl) propanoic acid) were purchased from Tocris Cookson (Bristol; UK). PCCG-IV ((2S,1'S,2'S,3'R)-2-(2"-carboxy-3'-phenylcyclopropyl)glycine) was a gift from Roberto Pellicciari. Glutamate-pyruvate transaminase (GPT) was purchased from Roche (Basel, Switzerland). Culture medium, fetal calf serum (FCS) and other products used for cell culture were purchased from GIBCO-BRL-Life Technologies, Inc. (Cergy Pontoise, France). $\left[{ }^{3} \mathrm{H}\right]$ myo-inositol $(23.4 \mathrm{Ci} / \mathrm{mol})$ was purchased from Amersham (Saclay, France).

\section{Plasmids and site-directed mutagenesis}

Plasmids encoding the wild-type $\mathrm{mGlu}_{5}$ subunits epitope tagged at their $\mathrm{N}$-terminal ends either with $\mathrm{HA}$ or $\mathrm{CMyc}$, under the control of a CMV promoter, were previously described $^{40}$. To obtain $\mathrm{mG5C1}$ and $\mathrm{mG5C2}$, the C-terminus of HA- or Myc-mGlu sa (His845Stop1172) was replaced by that of GABA $_{B 1 a}$ (Thr872-Stop961) and GABA $A_{B 2}$ (Phe760Stop941), respectively, amplified by PCR and subcloned between the Sphl and Xbal sites. Mutant subunits, carrying single or multiple mutations, were obtain using the Quick-Change ${ }^{\circledR}$ strategy (Stratagene, La Jolla, CA). The mG2/5C2 chimera was obtained by introducing a Pstl restriction site in both pRK-mG5C2 (before Cys510) and pRK-mGlu (after Ser498) using Quick-Change strategy and then by substitution of $\mathrm{mGlu}_{2}$ Pstl-Pstl fragment by that of mG5C2. All constructions were verified by DNA sequencing (Genaxis, Nîmes, France).

\section{Cell culture, transfection and Immunofluorescence}

HEK293 cells were cultured in Dulbecco's modified Eagle's medium supplemented with 10\% FCS (Fetal calf serum) and transfected by electroporation as described elsewhere ${ }^{41}$. Immunofluorescence assay was carried out as described previously ${ }^{40}$.

\section{Cell surface quantification by ELISA}

Experiments were conducted as described ${ }^{15}$. Twenty four hours after transfection, cells were washed, fixed with $4 \%$ paraformaldehyde and labelled with an anti-HA rat monoclonal antibody conjugated to peroxydase (clone 3F10; Roche, Basel, Switzerland) (0.5 $\mu \mathrm{g} / \mathrm{mL}$ ). Antibody was detected and quantified by chemiluminescence using Supersignal West Femto (Pierce, Rockford, IL) and a Wallac Victor ${ }^{2}$ luminescence counter (PerkinElmer Life and Analytical Science, Courtaboeuf, France). 


\section{Inositol phosphate determination}

Measurement of IP accumulation in transfected cells was performed in 96-well microplates as previously described ${ }^{25}$. Briefly, after overnight labeling with $\left[{ }^{3} \mathrm{H}\right]$ myo-inositol, cells were stimulated 30 minutes in the presence of $10 \mathrm{mM} \mathrm{LiCl}$, with or without indicated compounds. The reaction was stopped with $0.1 \mathrm{M}$ formic acid and IP produced were purified in 96 well plates by ion exchange chromatography. Radioactivity was measured using a Wallac 1450 MicroBeta microplate liquid scintillation counter (PerkinElmer Life and Analytical Science, Courtaboeuf, France). Results are expressed as the ratio between IP and the total radioactivity present in the membranes.

\section{Time Resolved-FRET experiments}

Time-resolved FRET experiments were conducted as described ${ }^{24}$. This methodology is based on the non-radiative energy transfer between rare earth cryptates such as europium $\left(\mathrm{Eu}^{3+}\right)$ cryptates and acceptor fluorophores such as AlexaFluor ${ }^{\circledR} 647$ (Molecular Probes). Briefly, cells expressing the indicated tagged receptor subunits were labeled with the monoclonal anti-HA (12CA5) and/or anti-myc (9E10; ATCC no. CRL-1729) antibodies carrying either $\mathrm{Eu}^{3+}$-Cryptate PBP or AlexaFluor ${ }^{\circledR} 647$ (provided by Cis Bio Intl Research, Bagnols/Ceze, France). After washing, total $\mathrm{Eu}^{3+}$ cryptate fluorescence and FRET signal were measured at 620 and $665 \mathrm{~nm}$, respectively, $50 \mu \mathrm{sec}$ after excitation at $337 \mathrm{~nm}$ with a nitrogen laser using a RubyStar spectrofluorimeter (BMG LabTechnologies, Champigny-surMarne, France). The ratio $R=\left[(\right.$ fluorescence $665 \mathrm{~nm} /$ fluorescence $\left.620 \mathrm{~nm}) \times 10^{4}\right]$ was computed. The specific signal over background called $\Delta \mathrm{F}$ was calculated using the following formula: $\Delta \mathrm{F}=($ Rpos - Rneg $) /($ Rneg $)$. Rneg corresponded to the ratio for the negative energy transfer control where excess unlabeled anti-myc monoclonal antibodies was added whereas Rpos corresponded to the ratio for the positive energy transfer control. Total fluorescence emitted by the bound AlexaFluor ${ }^{\circledR} 647$ conjugated antibodies was measured at $682 \mathrm{~nm}$ after excitation at $640 \mathrm{~nm}$ using an Analyst ${ }^{\mathrm{TM}}$ plate reader (Molecular Devices, St Gregoire, France).

\section{Intracellular calcium measurements}

Measurement of intracellular $\mathrm{Ca}^{2+}$ signal in transfected cells was performed in 96-well microplates as previously described ${ }^{25}$ using the $\mathrm{Ca}^{2+}$-sensitive fluorescent dye Fluo-4AM (Molecular Probes, Leiden, The Netherlands). Fluorescence signals (excitation $485 \mathrm{~nm}$, emission $525 \mathrm{~nm}$ ) were measured using the fluorescence microplate reader Flexstation (Molecular Devices, St Gregoire, France). The effect of added compounds was examined after 20 seconds of recording. 


\section{Data analysis}

The dose-response curves were fitted using Graph Pad (San Diego, CA) Prism program and the following equation for monophasic dose-response curves: $y=\left[\left(y_{\max }-y_{\min }\right) /\right.$ $\left.1+\left(x / E C_{50}\right) n_{H}\right]+y_{\min }$, where the $E C_{50}$ is the concentration of the compound necessary to obtain $50 \%$ of the maximal effect, and $n_{H}$ is the Hill coefficient. For biphasic dose-response curves, the following equation was used: $y=\left[\left(y_{p l}-y_{\min }\right) / 1+\left(x / E C_{50 L}\right) n_{H L}\right]+\left[\left(y_{\max }-y_{p l}\right) / 1+\right.$ $\left.\left(x / E C_{50 H}\right) n_{H H}\right]+y_{\min }$, where $y_{p l}$ represent the plateaued value, " $L$ " is indicative for the first component and " $\mathrm{H}$ " for the second of the curve.

All data represented correspond to means \pm SEM from one representative experiment performed in triplicate out of three.

\section{Molecular modeling}

3D model of the liganded mGlu 5 VFT was generated using the coordinates of the liganded closed form of mGlu1 VFT (pdb: 1ewkA) using MODELER 5.00 (Insight-II version 2000, Accelrys, San Diego, CA), as previously described ${ }^{16}$. Figures displaying structures were prepared using SwissPdbViewer program (v3.7 $)^{42}$. 


\section{References}

1. Cho, H.S. \& Leahy, D.J. Structure of the extracellular region of HER3 reveals an interdomain tether. Science 297, 1330-1333 (2002).

2. Cho, H.S. et al. Structure of the extracellular region of HER2 alone and in complex with the Herceptin Fab. Nature 421, 756-760 (2003).

3. Ogiso, H. et al. Crystal structure of the complex of human epidermal growth factor and receptor extracellular domains. Cell 110, 775-787 (2002).

4. Ferguson, K.M. et al. EGF activates its receptor by removing interactions that autoinhibit ectodomain dimerization. Mol Cell 11, 507-517 (2003).

5. He, X.-1., Chow, D.-c., Martick, M.M. \& Garcia, K.C. Allosteric activation of a spring-loaded natriuretic peptide receptor dimer by hormone. Science 293, 1657-1662 (2001).

6. van den Akker, F. et al. Structure of the dimerized hormone-binding domain of a guanylyl-cyclase-coupled receptor. Nature 406, 101-104 (2000).

7. van den Akker, F. Structural Insights into the Ligand Binding Domains of Membrane Bound Guanylyl Cyclases and Natriuretic Peptide Receptors. J Mol Biol 311, 923-937 (2001).

8. Tsuchiya, D., Kunishima, N., Kamiya, N., Jingami, H. \& Morikawa, K. Structural views of the ligand-binding cores of a metabotropic glutamate receptor complexed with an antagonist and both glutamate and Gd3+. Proc Natl Acad Sci U S A 99, 26602665 (2002).

9. Kunishima, N. et al. Structural basis of glutamate recognition by a dimeric metabotropic glutamate receptor. Nature 407, 971-977 (2000).

10. Dann, C.E. et al. Insights into Wnt binding and signalling from the structures of two Frizzled cysteine-rich domains. Nature 412, 86-90. (2001).

11. West, A.P., Jr., Llamas, L.L., Snow, P.M., Benzer, S. \& Bjorkman, P.J. Crystal structure of the ectodomain of Methuselah, a Drosophila $\mathrm{G}$ protein-coupled receptor associated with extended lifespan. Proc Natl Acad Sci U S A 98, 3744-3749 (2001).

12. Pin, J.P., Galvez, T. \& Prezeau, L. Evolution, structure, and activation mechanism of family 3/C G-protein-coupled receptors. Pharmacol Ther 98, 325-354 (2003).

13. O'Hara, P.J. et al. The ligand-binding domain in metabotropic glutamate receptors is related to bacterial periplasmic binding proteins. Neuron 11, 41-52 (1993).

14. Romano, C., Yang, W.L. \& O'Malley, K.L. Metabotropic glutamate receptor 5 is a disulfide-linked dimer. J Biol Chem 271, 28612-28616 (1996).

15. Kniazeff, J. et al. Locking the dimeric GABA(B) G-protein-coupled receptor in its active state. J Neurosci 24, 370-377 (2004).

16. Bessis, A.S. et al. Closure of the Venus flytrap module of mGlu8 receptor and the activation process: Insights from mutations converting antagonists into agonists. Proc Natl Acad Sci U S A 99, 11097-11102 (2002).

17. Kniazeff, J., Galvez, T., Labesse, G. \& Pin, J.P. No ligand binding in the GB2 subunit of the $\mathrm{GABA}(\mathrm{B})$ receptor is required for activation and allosteric interaction between the subunits. J Neurosci 22, 7352-7361 (2002).

18. Margeta-Mitrovic, M., Jan, Y.N. \& Jan, L.Y. A trafficking checkpoint controls GABA(B) receptor heterodimerization. Neuron 27, 97-106 (2000).

19. Pagano, A. et al. C-terminal interaction is essential for surface trafficking but not for heteromeric assembly of GABA(b) receptors. J Neurosci 21, 1189-1202 (2001).

20. Couve, A. et al. Intracellular retention of recombinant GABAB receptors. J Biol Chem 273, 26361-26367 (1998). 
21. Ray, K. \& Hauschild, B.C. Cys-140 Is critical for metabotropic glutamate receptor-1 (mGluR-1) dimerization. J Biol Chem 275, 34245-34251 (2000).

22. Tsuji, Y. et al. Cryptic dimer interface and domain organization of the extracellular region of metabotropic glutamate receptor subtype 1. J Biol Chem 275, 28144-28151 (2000).

23. Bazin, H., Trinquet, E. \& Mathis, G. Time resolved amplification of cryptate emission: a versatile technology to trace biomolecular interactions. Rev. Mol. Biotech. 82, 233-250 (2002).

24. Maurel, D. et al. Cell surface detection of membrane protein interaction with HTRF® technology. Anal Biochem (2004).

25. Goudet, C. et al. Heptahelical domain of metabotropic glutamate receptor 5 behaves like rhodopsin-like receptors. Proc Natl Acad Sci U S A 101, 378-383 (2004).

26. Pin, J.-P. \& Acher, F. The metabotropic glutamate receptors: structure, activation mechanism and pharmacology. Cur. Drug Targets - CNS \& Neur. Dis. 1, 297-317 (2002).

27. Havlickova, M. et al. The intracellular loops of the GB2 subunit are crucial for Gprotein coupling of the heteromeric gamma-aminobutyrate B receptor. Mol Pharmacol 62, 343-350 (2002).

28. Chang, W., Chen, T.H., Pratt, S. \& Shoback, D. Amino acids in the second and third intracellular loops of the parathyroid $\mathrm{Ca} 2+$-sensing receptor mediate efficient coupling to phospholipase C. J Biol Chem 275, 19955-19963 (2000).

29. Francesconi, A. \& Duvoisin, R.M. Role of the second and third intracellular loops of metabotropic glutamate receptors in mediating dual signal transduction activation. $J$. Biol. Chem. 273, 5615-5624 (1998).

30. Galvez, T. et al. Mapping the agonist binding site of GABAB type 1 subunit sheds light on the activation process of GABAB receptors. J. Biol. Chem. 275, 41166-41174 (2000).

31. Marshall, F.H., Jones, K.A., Kaupmann, K. \& Bettler, B. GABAB receptors - the first 7TM heterodimers. Trends Pharmacol Sci 20, 396-399 (1999).

32. Galvez, T. et al. Allosteric interactions between GB1 and GB2 subunits are required for optimal GABA(B) receptor function. Embo J 20, 2152-2159 (2001).

33. Duthey, B. et al. A single subunit (GB2) is required for G-protein activation by the heterodimeric GABAB receptor. J. Biol. Chem. 277, 3236-3241 (2002).

34. Pin, J.-P. \& Bockaert, J. Part IV: Type III Family of GPCRs - Metabotropic glutamate receptors. in Structure-function of G-protein coupled receptors in the CNS (eds. Pangalos, M. \& Davies, C.) 586-616 (Oxford University press, Oxford, 2002).

35. Kubo, Y., Miyashita, T. \& Murata, Y. Structural basis for a $\mathrm{Ca}^{2+}$-sensing function of the metabotropic glutamate receptors. Science 279, 1722-1725 (1998).

36. Nelson, G. et al. Mammalian Sweet Taste Receptors. Cell 106, 381-390 (2001).

37. Li, X. et al. Human receptors for sweet and umami taste. Proc Natl Acad Sci U S A 99, 4692-4696. (2002).

38. Zhao, G.Q. et al. The receptors for mammalian sweet and umami taste. Cell 115, 255266 (2003).

39. Nelson, G. et al. An amino-acid taste receptor. Nature 416, 199-202. (2002).

40. Ango, F. et al. A simple method to transfer plasmid DNA into neuronal primary cultures: functional expression of the mGlu5 receptor in cerebellar granule cells. Neuropharmacology 38, 793-803 (1999).

41. Brabet, I. et al. Comparative effect of L-CCG-I, DCG-IV and gamma-carboxy-Lglutamate on all cloned metabotropic glutamate receptor subtypes.

Neuropharmacology 37, 1043-1051 (1998). 
42. Guex, N. \& Peitsch, M.C. SWISS-MODEL and the Swiss-PdbViewer: an

environment for comparative protein modeling. Electrophoresis 18, 2714-2723 (1997). 


\section{Legends}

Figure 1: Different conformations of the mGlu VFT dimer determined by X-ray crystallography. The different conformations observed under various crystallization conditions are represented in the same orientation: lobes-I of both protomers on the top and lobes-II on the bottom. Chain A (yellow) is in front and chain B (blue) is in the back. The upper panel shows the structures in the 'resting' open-open orientation (Roo): either unliganded (right (pdb code: 1ewt)) or in the presence of a competitive antagonist, MCPG (left (pdb code: 1iss)). In the lower panel, the structures are in the so-called 'active' orientation: closed-open (Aco) in the presence of glutamate (right (pdb code: 1ewk)), and closed-closed (Acc) in the presence of both glutamate and $\mathrm{Gd}^{3+}$ (left (pdb code: 1 isr)). Note that the Aco structure has also been observed without ligand ( $p d b$ code: 1ewv).

Figure 2: Cellular localization and function of $m G 5 C 1$ and $m G 5 C 2$ chimeras. (a): Schematic representation of wild-type and chimeric subunits. (b): Immunofluorescence staining of HA epitope on permeabilized (upper) or intact cells (lower) expressing either HA$\mathrm{mG} 5 \mathrm{C} 1$ alone or together with the untagged mG5C2. Note the tags are inserted at the $\mathrm{N}$ terminus of the proteins and are therefore accessible to antibodies in intact cells only if the receptor is at the cell surface. (c): Quantification of cell surface expression of HA-tagged subunits by ELISA on intact cells transfected with indicated subunits. d: IP production measurement upon stimulation with increasing concentrations of quisqualate on cells expressing the indicated chimeras. As expected, cells expressing the intracellular mG5C1 $(\Delta)$ are not activated, whereas both the expression of either mG5C1 $1_{A S A}(\boldsymbol{\Delta})$ or mG5C2 (O) lead to a dose dependant stimulation.

Figure 3: Dimerization of $m G 5 C 1$ and $m G 5 C 2$ chimeras at the cell surface. (a): Schematic representation of the different dimeric combinations and their localization in cells expressing mG5C1 and mG5C2. (b): Representation of FRET signal ( $\triangle \mathrm{F}$ in \%) detected on intact cells expressing the indicated epitope tagged subunits using $\mathrm{Eu}^{3+}$-Cryptate PBP labeled anti-HA and AlexaFluor ${ }^{\circledR} 647$ anti-myc antibodies. In the "mix" condition, cells coexpressing HA-mG5C1 and myc-mG5C2 were separately labeled with either donor-labeled anti-HA or acceptor-labeled anti-myc antibodies and mixed just before measuring the signal. (c): The expression level of each subunit at the cell surface in the same cells as in $\mathbf{b}$ was determined by measuring the fluorescence remaining after washing of free antibodies. (d): FRET signals ( $\triangle \mathrm{F}$ in \%) measured between $\mathrm{HA}$ and myc epitopes ( $\square)$ or between two HA epitopes $(O)$ are represented as a function of cell surface expression of HA-mG5C1 coexpressed with myc-mG5C2. 
Figure 4: Mutation of the $m \mathrm{Glu}_{5}$ binding site. (a): Zoomed view on the binding site of a three-dimensional model of the mGlu $_{5}$ VFT in a closed conformation with docked glutamate. Residues directly contacting glutamate are shown. (b): IP production measurement in cells expressing the indicated $\mathrm{mGlu}_{5}$ mutant after stimulation with various concentration of quisqualate.

Figure 5: Biphasic dose-response curves of "heterodimeric" $m$ Glu $u_{5}$ receptor. (a): Schematic representation and localization of the receptor combinations in cells coexpressing mG5C1 and mG5C2 mutated on its binding site (mG5C2 (mut)). As illustrated, the only combination potentially functional is the heterodimer mG5C1:mG5C2 (mut). (b): IP production and (c) $\mathrm{Ca}^{2+}$ release measurement are plotted as a function of quisqualate

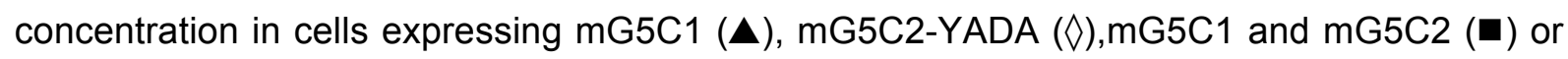
mG5C1 and mG5C2-YADA (O).(d): IP production in cells co-expressing mG5C1 and mG5C2-YADA ( $\boldsymbol{\square})$, mG5C2-YATA (O) or mG5C2-SATA $(\boldsymbol{\Delta})$ after stimulation with increasing concentrations of quisqualate.

Figure 6: Active efficacy of the Aco conformation of the VFTs dimer. (a): Schematic representation of wild-type and chimeric subunits. $\mathrm{mG} 2 / 5 \mathrm{C} 2$ is composed of VFT of $\mathrm{mGlu}_{2}$ (hatched), $\mathrm{CRD}$ and $\mathrm{HD}$ of $\mathrm{mGlu}_{5}$ (grey) and $\mathrm{GABA}_{\mathrm{B} 2}$ C-terminus (dotted line). (b): Representation of combination present in the plasma membrane of cells expressing $\mathrm{mG} 5 \mathrm{C} 1$ and $\mathrm{mG} 2 / 5 \mathrm{C} 2$. Note that the $\mathrm{mG} 2 / 5 \mathrm{C} 2$ homodimers present at the cell surface are inactive in the absence of $\mathrm{mGlu}_{2}$ agonist and in the presence of a $\mathrm{mGlu}_{2}$ antagonist. (c): IP production obtained upon stimulation with increasing concentrations of quisqualate in the presence $(O)$ or not $(\boldsymbol{\square})$ of the $\mathrm{mGlu}_{2}$ antagonist PCCG-IV. Similar results were obtained with other $\mathrm{mGlu}_{2}$ specific antagonists (not shown).

Figure 7: Cis and Trans-activation within mGlu receptors. (a): IP production in cells expressing $\mathrm{mG} 5 \mathrm{C} 1$ and $\mathrm{mG} 5 \mathrm{C} 2$ bearing either no mutation (匹), i3 loop mutation in $\mathrm{mG} 5 \mathrm{C} 1$ $(\bullet)$ or in $\mathrm{mG5C2}(\diamond)$ upon application of various concentration of quisqualate. Values were normalized using the ELISA signal obtained with the same cells in the same experiment and expressed as percent of the maximal effect obtained with the control receptor combination. (b): Representation of different signal transduction possibilities within the dimer: activation of one VFT may activate the underlying (cis-activation) or the adjacent (trans-activation) HD. (c): Similar as in a but with cells expressing wild-type or mutated mG5C1 and mG5C2-YADA. Both the first (in black) and the second (in red) components of the response are still present 
if one subunit bears the i3 mutation but are decreased. (d): Signal transduction in combinations used in c: the black and red arrows correspond to the HD activation produced by ligand binding in the wild-type or mutated VFT, respectively.

Figure 8: Comparison of the active efficacy of Aco and Acc conformations. (a): On the left, schematic representation of combinations present at the surface of cells co-expressing $m G 5 C 1$ and $m G 2 / 5 C 2-i 3$. Homodimers $m G 2 / 5 C 2-i 3$ are inactive because they failled to couple to $G$ proteins. Note that quisqualate will activate mG5C1 VFT only, whereas the $\mathrm{mGlu}_{2}$ specific agonist (DCG-IV) will activate mG2/5C2-i3 VFT only. On the right, IP production measured in cells co-expressing mG5C1 and mG2/5C2-i3 upon stimulation with increasing concentrations of quisqualate $(\mathbf{\square}), \mathrm{DCG}-\mathrm{IV}$ in the presence of quisqualate $\left(10^{-4}\right.$ $M)(O)$ or DCG-IV alone $(\Delta)$. (b): Same as in a, but with glutamate that activates both VFT, and LY341495 an $\mathrm{mGlu}_{2}$ antagonist. On the right, IP production measured in cells coexpressing $\mathrm{mG} 5 \mathrm{C} 1$ and $\mathrm{mG} 2 / 5 \mathrm{C} 2-\mathrm{i} 3$ upon stimulation with increasing concentrations of LY341495 $(\mathrm{O})$ in the presence of $3.10^{-3} \mathrm{M}$ glutamate, or with increasing concentrations glutamate $(\mathbf{\square})$. 
Figure 1

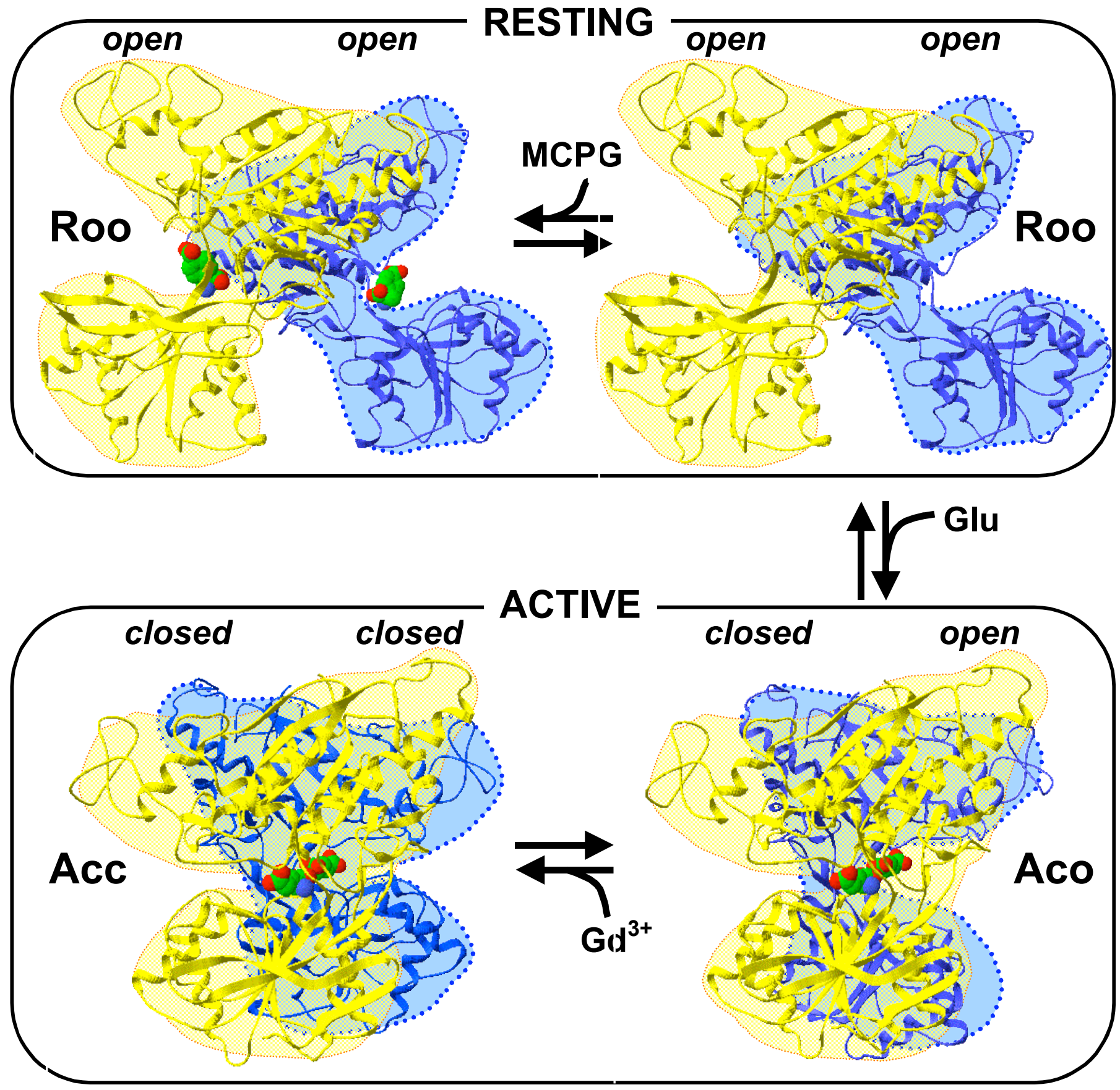


Figure 2

a

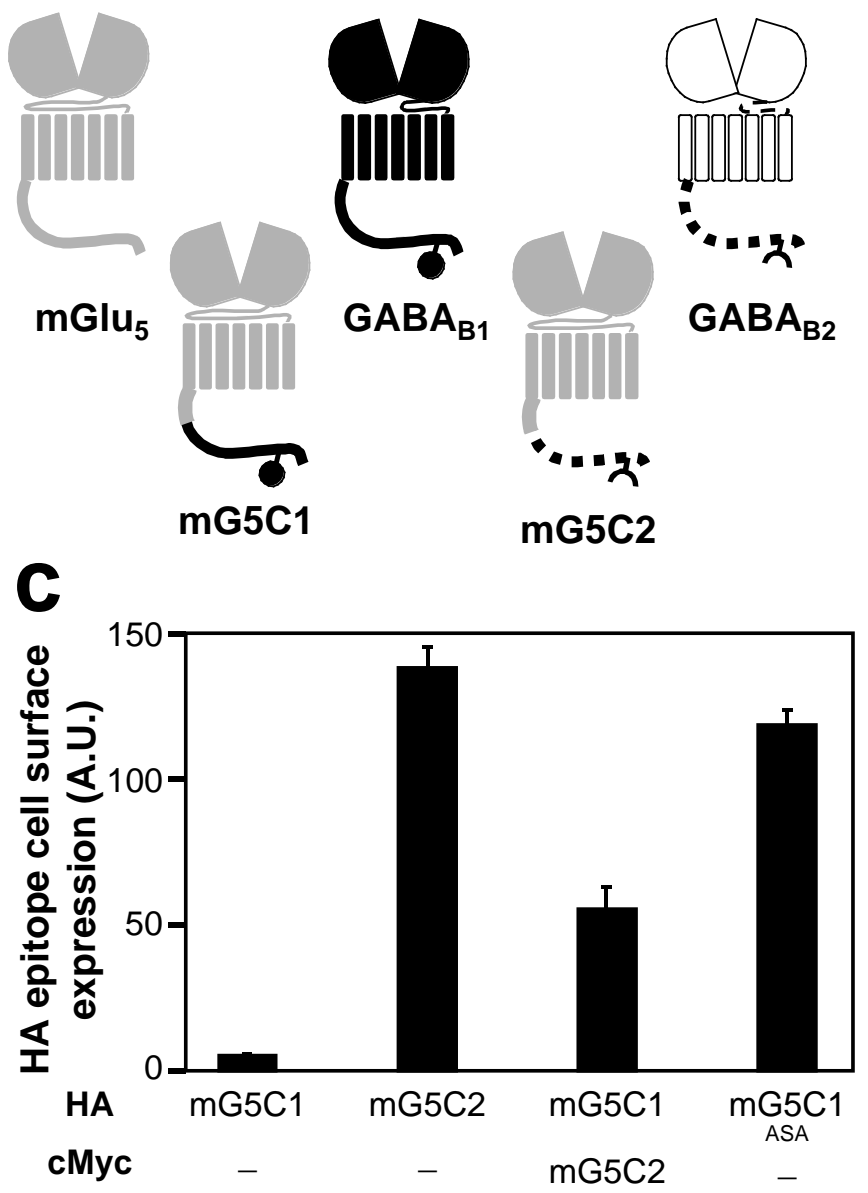

b

HA-mG5C1

HA-mG5C1+mG5C2

permeabilized cells
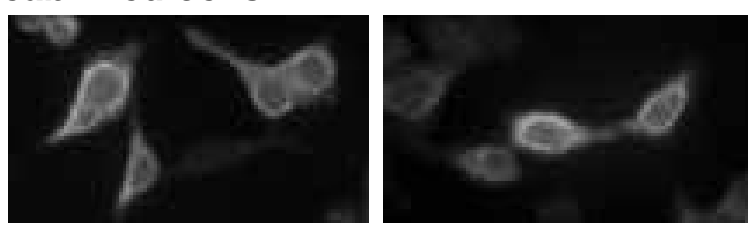

intact cells
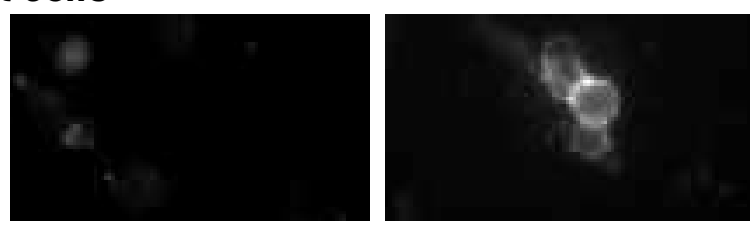

0

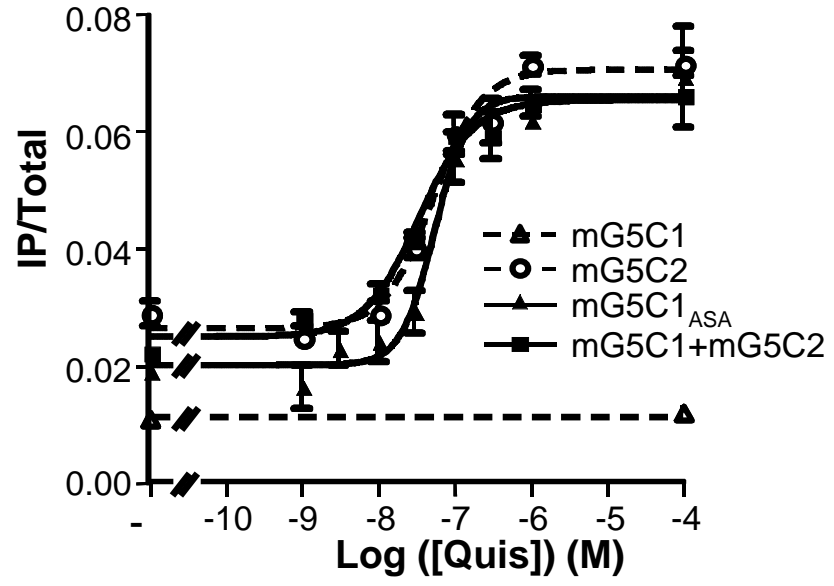


Figure 3

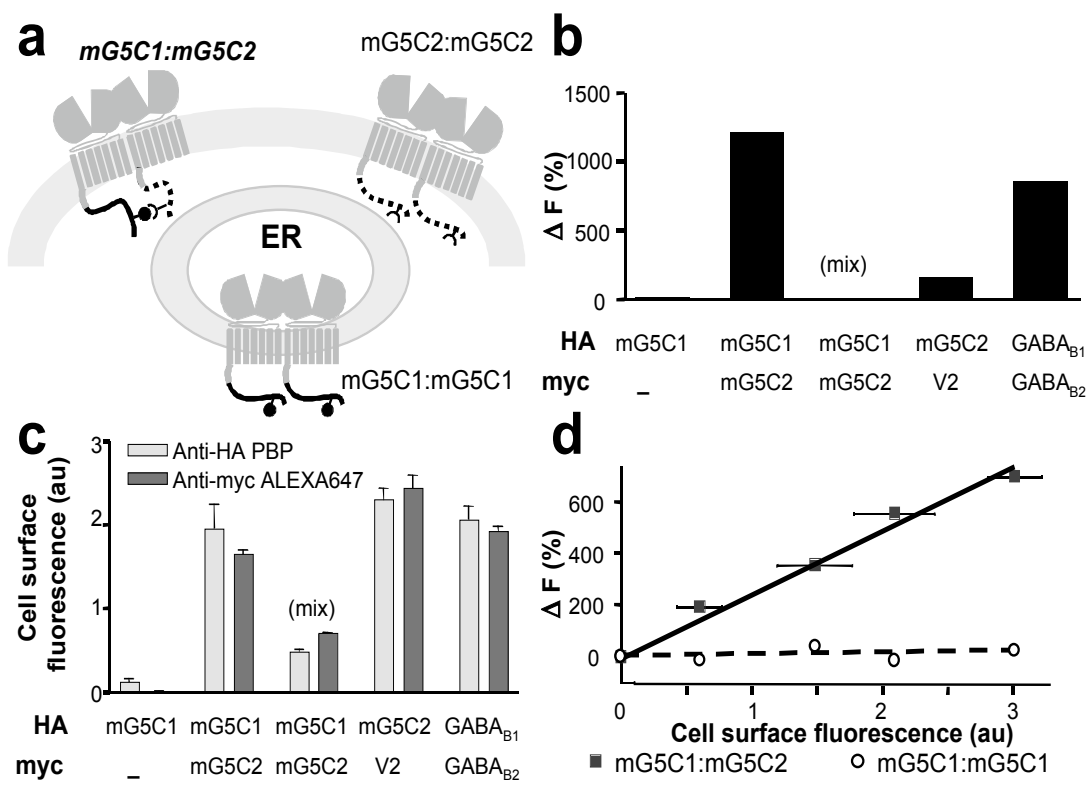


Figure 4
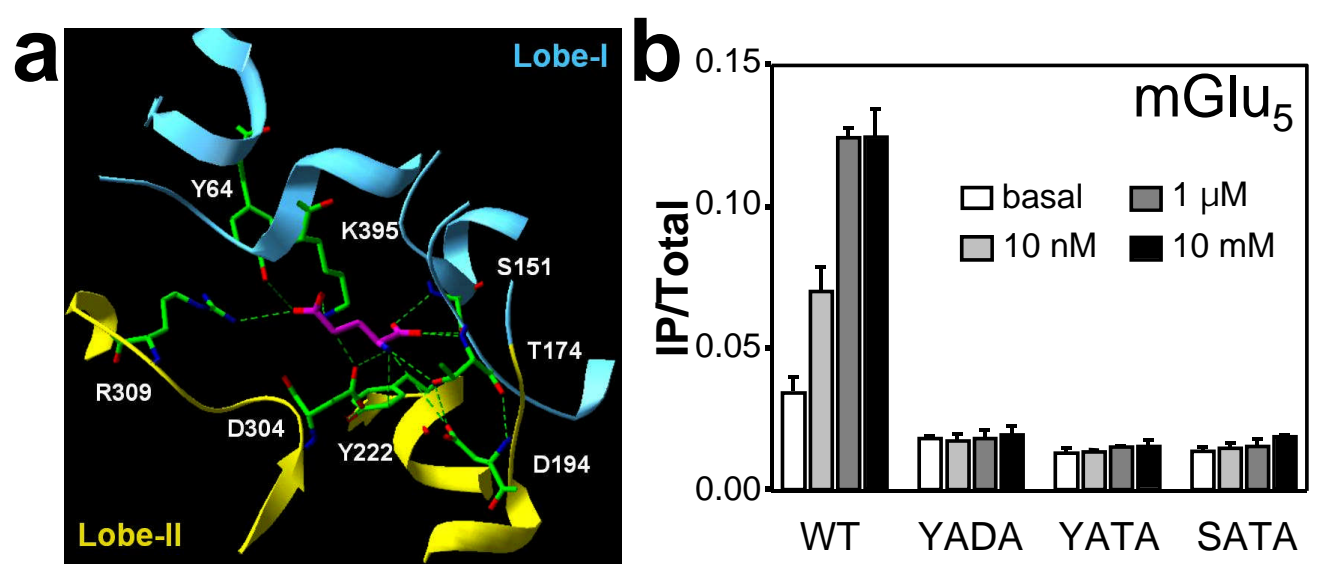
Figure 5
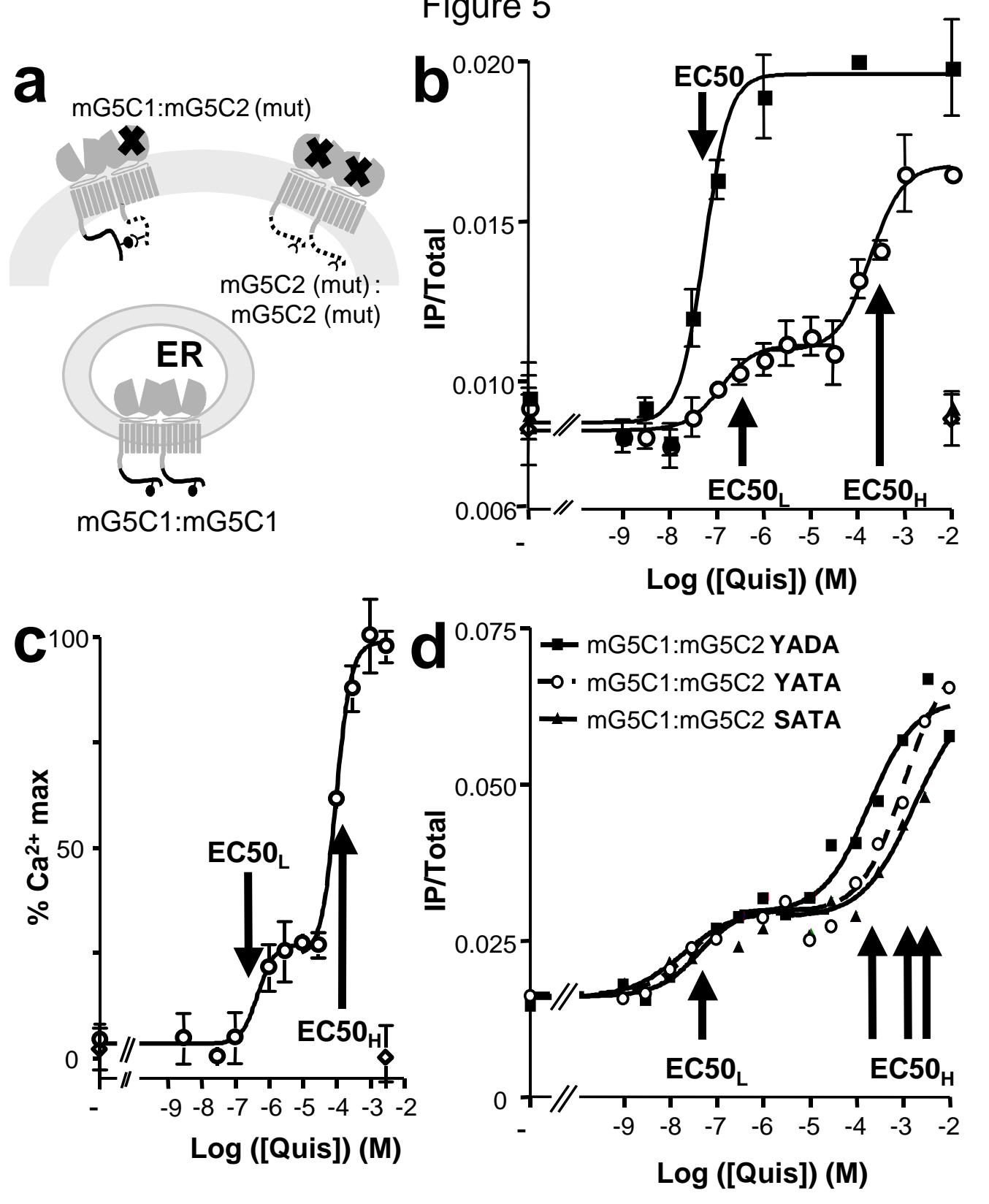
Figure 6

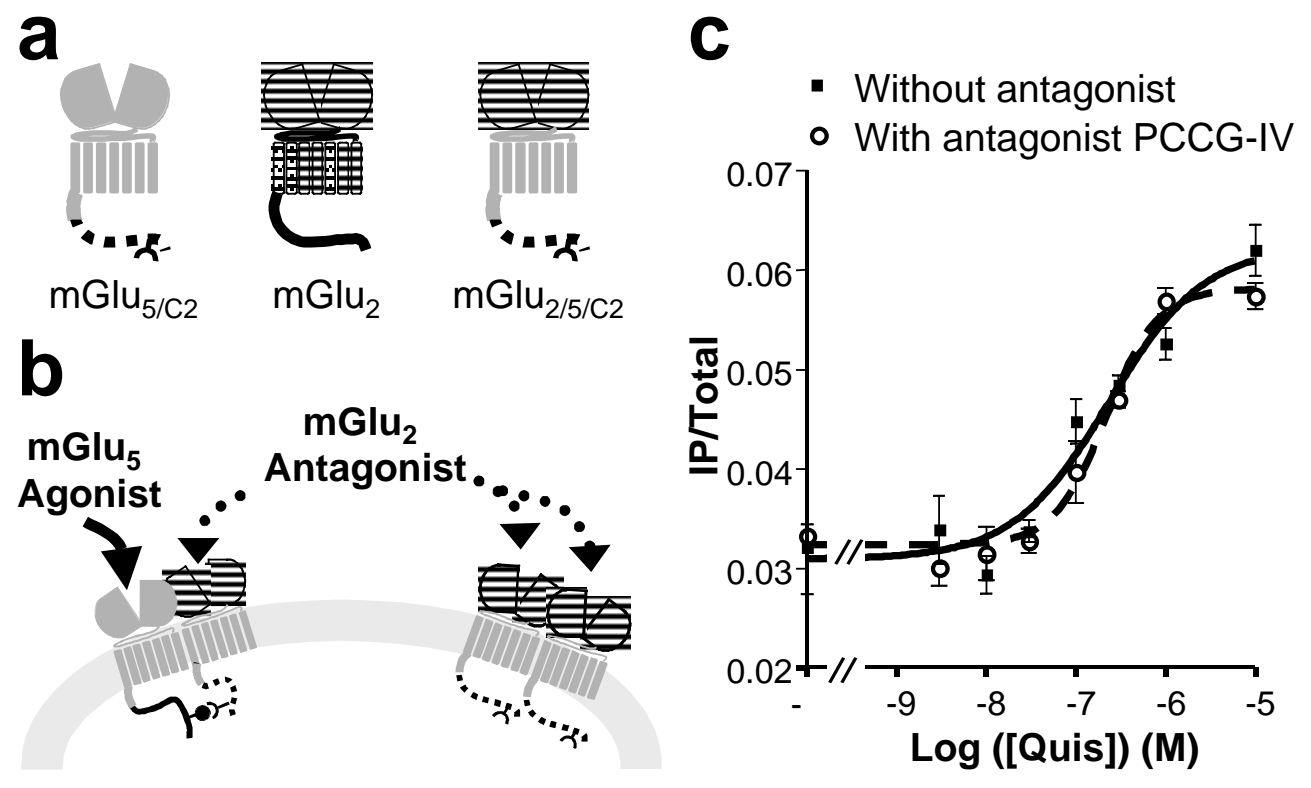


Figure 7

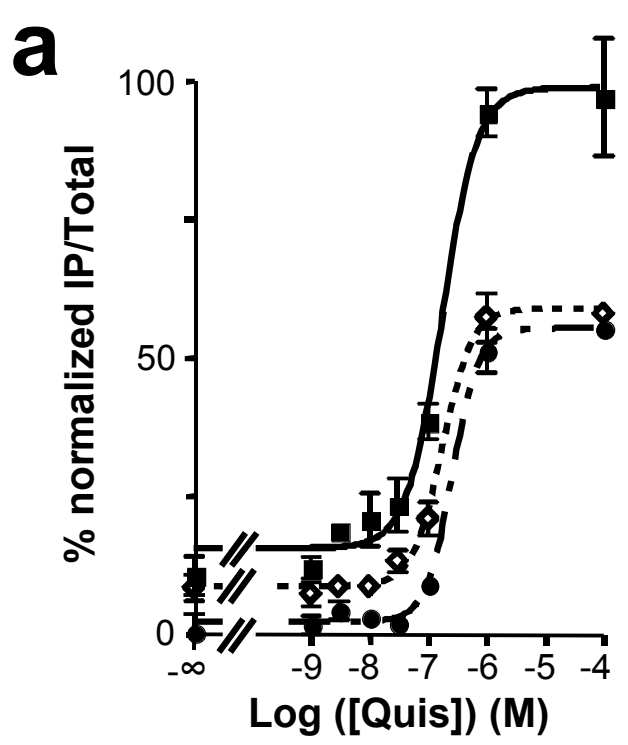

b
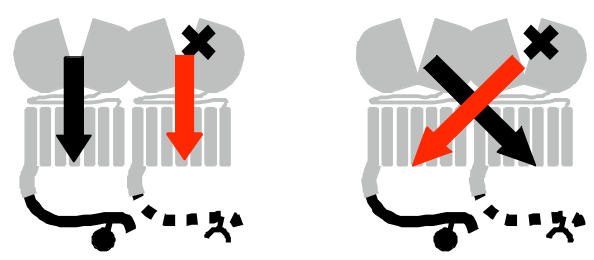

Cis-activation Trans-activation

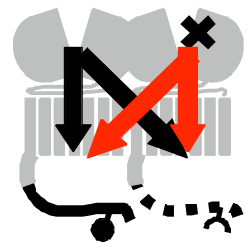

Cis- and Trans-activation
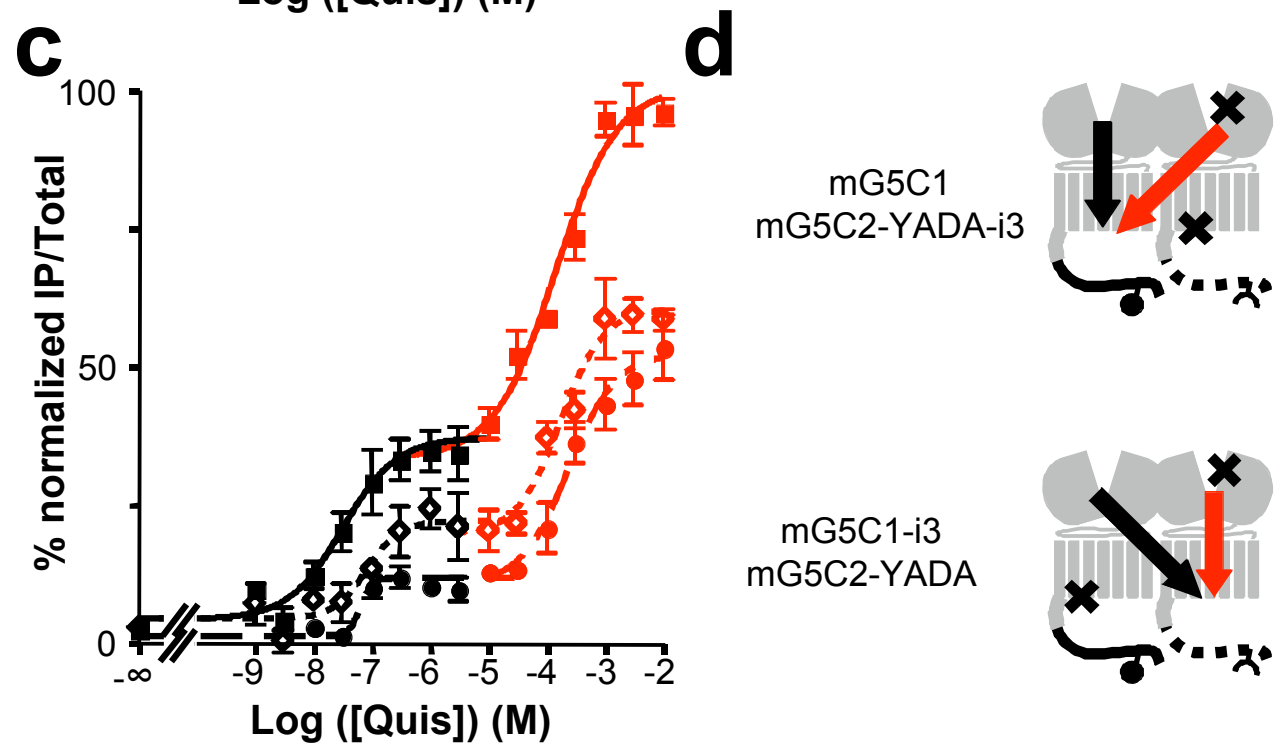

mG5C1-i3 mG5C2-YADA

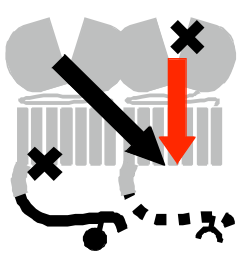


Figure 8

a
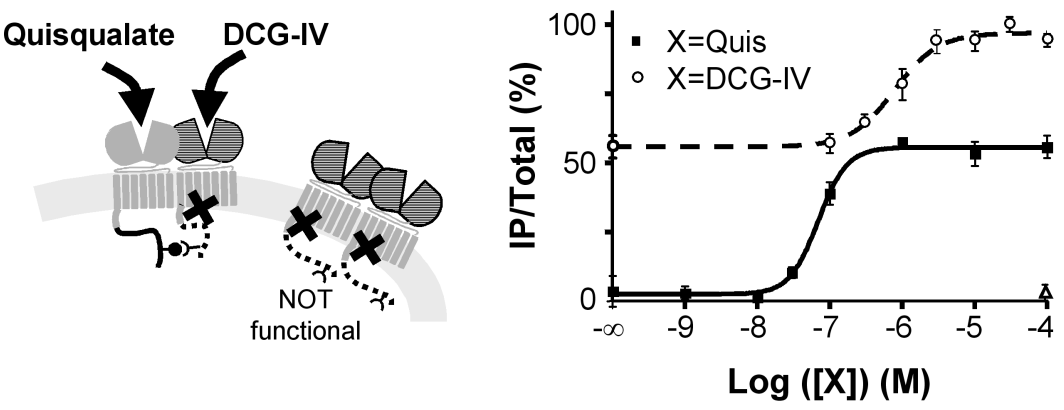

Glutamate LY341495
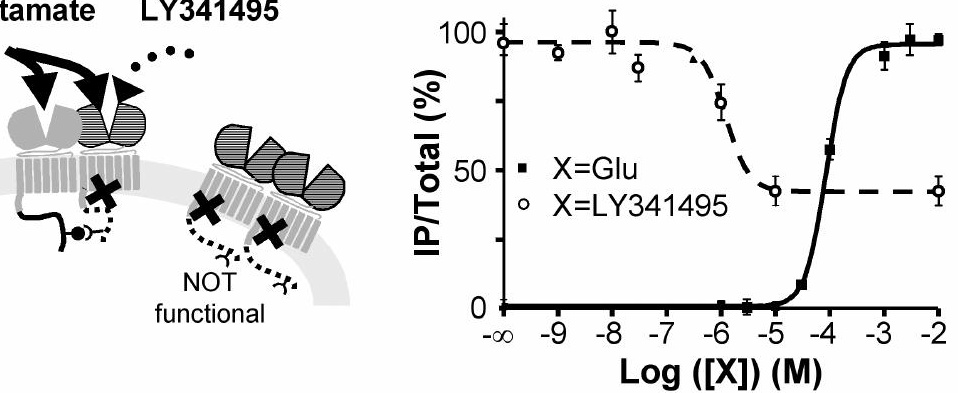